\title{
Lived Clinical Education Experiences of Professional Master's Athletic Training Program Graduates
}

\author{
Laura A. Wamsley \\ Concord University, Iwamsley@concord.edu \\ Kimbery Brown \\ Radford University, kbrown849@radford.edu \\ Jill A. Nolan \\ Concord University, jnolan@concord.edu
}

Follow this and additional works at: https://nsuworks.nova.edu/ijahsp

Part of the Curriculum and Instruction Commons, Higher Education Commons, and the Medicine and Health Sciences Commons

\section{Recommended Citation}

Wamsley LA, Brown K, Nolan JA. Lived Clinical Education Experiences of Professional Master's Athletic Training Program Graduates. The Internet Journal of Allied Health Sciences and Practice. 2020 Jan 01;18(3), Article 2.

This Manuscript is brought to you for free and open access by the College of Health Care Sciences at NSUWorks. It has been accepted for inclusion in Internet Journal of Allied Health Sciences and Practice by an authorized editor of NSUWorks. For more information, please contact nsuworks@nova.edu. 


\title{
Lived Clinical Education Experiences of Professional Master's Athletic Training Program Graduates
}

\begin{abstract}
Purpose: Clinical education has been identified as a key aspect in the professional preparation of athletic trainers. The literature, however, has focused on clinical education at the undergraduate level rather than the graduate level, which is the future population of all CAATE-accredited athletic training programs. This study sought to describe the experiences of those who have completed athletic training clinical education at the master's level, specifically focusing on the type of learning experiences they were granted and what influence the preceptor and the setting played in the overall experience. Method: This was a phenomenology study. Twelve graduates of CAATE-accredited professional master's athletic training programs served as participants. All participants graduated after Spring 2014 and completed clinical education as a degree requirement. Three methods of data collection were utilized, including semistructured interviews, prompted journaling and asynchronous online focus group discussion boards. Data was analyzed using a phenomenological reduction approach. Credibility of the data was confirmed with member checking, peer review and data triangulation. Results: Clinical education was determined to be a significant contributor to professional preparation of professional master's athletic training students. Hands on-experiences, active preceptors and variety in clinical setting and opportunity were all cited as contributors to the success of clinical education. Participants described their experience as a significant commitment but valuable. Conclusions: Our findings suggest that clinical education should continue to be a requirement at the graduate level and that the clinical education curriculum should be designed to encourage hands-on learning and variety.
\end{abstract}

\section{Author Bio(s)}

Laura Wamsley, EdD, ATC is an Assistant Professor of Athletic Training at Concord University. She also serves as the Clinical Education Coordinator for the Athletic Training Program at Concord University.

Kimberly Brown , DPN, RN, CNE, NEA-BC is an Associate Professor in the School of Nursing at Radford University.

Jill Nolan, PhD is an Associate Professor in the Department of Health Sciences at Concord University. She also serves as the Master's of Arts in Health Promotion Program Coordinator. 


\title{
TIAHSP \\ The Internet Joumnal of Allied Health Sciences and Practice \\ Dedicated to allied health professional practice and education
}

Vol. 18 No. 3 ISSN 1540-580X

\section{Lived Clinical Education Experiences of Professional Master's Athletic Training Program Graduates}

\author{
Laura A. Wamsley ${ }^{1}$ \\ Kimberly Brown ${ }^{2}$ \\ Jill Nolan ${ }^{1}$ \\ 1. Concord University \\ 2. Radford University \\ United States
}

\begin{abstract}
Purpose: Clinical education has been identified as a key aspect in the professional preparation of athletic trainers. The literature, however, has focused on clinical education at the undergraduate level rather than the graduate level, which is the future population of all CAATE-accredited athletic training programs. This study sought to describe the experiences of those who have completed athletic training clinical education at the master's level, specifically focusing on the type of learning experiences they were granted and what influence the preceptor and the setting played in the overall experience. Method: This was a phenomenology study. Twelve graduates of CAATE-accredited professional master's athletic training programs served as participants. All participants graduated after Spring 2014 and completed clinical education as a degree requirement. Three methods of data collection were utilized, including semi-structured interviews, prompted journaling and asynchronous online focus group discussion boards. Data was analyzed using a phenomenological reduction approach. Credibility of the data was confirmed with member checking, peer review and data triangulation. Results: Clinical education was determined to be a significant contributor to professional preparation of professional master's athletic training students. Hands on-experiences, active preceptors and variety in clinical setting and opportunity were all cited as contributors to the success of clinical education. Participants described their experience as a significant commitment but valuable. Conclusions: Our findings suggest that clinical education should continue to be a requirement at the graduate level and that the clinical education curriculum should be designed to encourage hands-on learning and variety.
\end{abstract}

Keywords: athletic training education, clinical preceptors, clinical site, hands-on learning, clinical education 


\section{INTRODUCTION}

Clinical education is a vital contributor in the preparation of professional athletic trainers. ${ }^{1}$ Historically, athletic training (AT) education has been steeped with more clinical education than didactic instruction. ${ }^{2}$ This is in contrast to that of other medical professions which traditionally showed a greater emphasis on classroom education. ${ }^{2}$ Laurent and Weidner found that entry-level certified athletic trainers perceive that approximately $53 \%$ of their entry-level professional development came from clinical education, making it a significant portion of their education. ${ }^{2}$ In a similar study involving AT students, they contributed much of their confidence in patient care to their clinical experiences. ${ }^{3}$ Clinical education contributes to realization of the role of an athletic trainer and professional socialization. ${ }^{1}$ It has also been stated that students who had completed clinical education experiences felt they benefited by being able to apply skills they first had been exposed to in coursework. ${ }^{1}$ Attributes that contribute to a student's overall experience and learning are positive professional role-modeling, supervised autonomy, and the use of teachable moments to encourage the development of critical thinking skills. ${ }^{4}$

Several components of clinical education contribute to a successful clinical experience. They include the student role, the preceptor role, and the clinical setting. ${ }^{1,4-6}$ Clinical experience hours will be most beneficial and encourage optimal learning when the student chooses to actively participate and take advantage of hands-on learning experiences that are presented. Students also report benefits from developing a strong relationship with the clinical preceptor to whom they were assigned. ${ }^{4,5,7,8}$ By developing a strong relationship with the supervising clinical preceptor, the student will feel more comfortable asking questions, seeking out learning opportunities, and requesting feedback, all of which will contribute to a better overall learning experience. ${ }^{9}$ Clinical preceptors should encourage active participation in clinical experiences. The clinical preceptor should also actively participate in clinical rotations to encourage students to observe, ask questions, practice skills, and reflect upon what they have learned. ${ }^{1,4,7}$ Preceptors serve as a mentor to students and provide opportunity for professional socialization. ${ }^{1,10}$

The Commission on Accreditation of Athletic Training Education (CAATE) announced in 2015 that the new degree requirement for AT certification would be a master's degree. ${ }^{11}$ This mandate has resulted in many undergraduate programs making the transition to the graduate level to meet accreditation standards. There has been limited research in the area of master's level AT students and their clinical education. There are noted differences in the learning preferences and motivations of graduate and undergraduate students. ${ }^{12,13}$ These differences support the need to evaluate the role that clinical education plays specifically in the education of professional master's AT students. The purpose of this study was to explore that role and gain insight in the experiences of those who have already completed clinical education as a professional master's AT student. Guiding our research were the following questions: 1) How do professional master's AT program graduates describe their experiences in clinical education? and 2) What influence does the learning opportunities, clinical preceptors, and clinical setting have on the overall experience of clinical education.

\section{METHODS}

\section{Research Design}

We utilized a transcendental phenomenological approach to investigate the experiences of athletic trainers who graduated from professional master's AT programs, specifically focusing on their clinical education experiences. This method of research allowed us to collect stories and real life experiences from those who had lived this phenomenon. ${ }^{14,15}$ We collected data from a small number of participants, allowing us to become immersed in the participant's experiences and identify those experiences that were common and shared. ${ }^{14}$

\section{Participants}

Before we recruited participants, we received approval from the institutional review board. We chose purposeful sampling to ensure that participants met the set criteria for participation. ${ }^{14}$ Participants were recruited using convenience and snowball sampling procedures. ${ }^{14}$ We used both professional and social networks to recruit participants who fit the inclusion criteria. Snowball sampling occurred when participants and other professional contacts recommended others who met the criteria for participation. ${ }^{14}$ The inclusion criteria were those who had completed a CAATE-accredited professional master's AT program, graduating in the spring 2014 or after and completed clinical education as a part of their formal education. Possible participants were screened with a written survey to ensure they met the criteria for inclusion. Twelve participants met the criteria and participated in the data collection process. Of the 12 participants, 10 were female and 2 were male. Two participants graduated following the spring 2014 academic semester, one after spring 2016, five following spring 2017, and four following spring 2018. Six different CAATE-accredited professional master's AT programs were represented. The professional master's AT programs and the respective associated clinical sites represented were from a variety of athletic competition levels; including NAIA and all NCAA levels and a variety of geographical areas. The clinical sites in which participants completed clinical experiences included collegiate, high school, professional sports, and physical therapy clinics. 


\section{Data Collection Procedures}

We collected data using three different methods: semi-structured interviews, prompted journaling and asynchronous online focus group discussion boards. ${ }^{14,16,17}$ These methods were designed to garner description-rich data that could be used to create a textual explanation of the phenomenon of completing clinical education in a professional master's AT program. ${ }^{14}$ Each participant was scheduled individually for a semi-structured interview with the lead researcher. We conducted the interviews in a variety of ways, including in-person, over the phone, and video conferencing. An independent company was hired to complete the transcription of the interviews. We began data analysis at the time of the interviews by taking field notes. After each interview, we sent each participant two journaling prompts to respond to and return. The interview prompts were 1) Identify one preceptor that you feel was influential in your learning during clinical education and explain the role they played in learning and overall experience during clinical education; and 2) Describe your most influential clinical site. Why was this site significant? How did this site prepare or fail to prepare you for clinical practice?

After a majority of the interviews had been conducted, we launched an online asynchronous focus group discussion board for all study participants. All participants were given pseudonyms to use on this platform to protect their identity. ${ }^{17}$ We chose this method of data collection to encourage conversation among members of the phenomenon that might create re-surfacing of memories that may not have previously been mentioned in the interviews or journals. Because of the nature of the AT profession, geographical variances and the challenge of scheduling a time that all participants could be available for a real-time focus group an asynchronous focus group was chosen as the most realistically possible method. ${ }^{17}$ Three separate discussion boards were created with three separate prompts to elicit discussion on multiple aspects of clinical education. The prompts asked participants to talk about their favorite memory of their AT clinical education, what they believed were characteristics of a strong clinical education experience, and what they felt should be requirements for all students during clinical education experiences. All participants were asked to make an initial post for each prompt and then respond to and develop conversation with fellow participants.

\section{Data Analysis}

We analyzed data using the principles of phenomenological reduction. ${ }^{15}$ Using the raw data, key phrases were given a code, which were eventually funneled down into four identified themes. We read through the raw data multiple times assigning simple codes to the phrases that were thought to be useful in answering the designated research questions. Only codes that appeared multiple times were used to develop the themes, as they were identified as shared experiences. After we felt confident in our theme development, we used the themes to write a description of the phenomenon and the types of learning experiences the participants experienced during the phenomenon.

\section{Establishing Trustworthiness}

We used multiple methods to ensure credibility and dependability in this study. Credibility was addressed through data triangulation. We compared data from all three data collection methods, identifying common codes and themes found across the methods.

We demonstrated dependability and confirmability through the use of member checking and peer review. All participants received a copy of their interview transcripts to review and edit should they feel anything in the transcripts mis-represented their experience. At the conclusion of our data analysis, we also sent them the identified themes and the textual description of the phenomenon for their review and comment if they felt there was inaccuracy. In addition to member-checking, we also had a peer-reviewer read through the data and confirm our analysis.

We feel that this study also demonstrates strong transferability. Though the overall number of participants was small compared to the number of people who share this phenomenon, and there was a disproportionate number of males to females, the participant pool demonstrated a strong variety. Participants represented multiple athletic training programs (ATPs) of varied size, location, and curriculum design.

\section{RESULTS}

Our analysis revealed that clinical education plays a vital role in the professional development of professional master's AT students. Contributing to that development are the preceptors, the clinical site, and the experiences that were afforded to the students. Four themes were identified in the analysis: confidence, access to educational resources and settings, mentorship and professional socialization, and commitment. (Figure 1). 
Confidence

Access to Educational

Resources and Settings

Mentorship and

Professional

Socialization

Commitment
- Real-life experiences create hands-on learning

- Hands-on learning opportunities provide experiences that students can reflect on and recived feedback from

- Supervised autonomy and increasing responsibility boosts confidence in students

- The amount and type of equipment available at a clinical site can influence the experience

-Variety in patient populations and preceptors/mentors was valued

- Professionalism should be demonstrated by preceptors

- Preceptors should demonstrate a willingness to teach and a desire to challenge the students

- Hard work and time commitment contribute to effect of experience

- High standards for the students should be created and enforced during clinical education

Figure 1. Emergent Themes of the Study

\section{Theme 1: Confidence}

Discussions centered on the idea that clinical education promoted confidence in the participants for when they would practice autonomously as a certified athletic trainer. The hands-on learning that they received during clinical experiences helped them to feel confident that they could perform the needed skills to act as a competent athletic trainer. Contributors to the building of confidence included increasing responsibility through-out clinical experiences, reflection on experiences, feedback received from preceptors, and being thrown-into situations as students with supervised autonomy. Several participants shared stories of moments when they felt confidence develop. These stories were about times the students completed their first full evaluation, developed a treatment plan, and had to report an injury to a coach or parent. These types of experiences provided hands-on lessons that allowed the students to develop feelings of confidence in their clinical abilities. Several participants reported that though they might have learned the knowledge or skill in the classroom originally; in their clinical experiences is when they felt they actually mastered the skill because of the hands-on and real-life aspects.

\section{Theme 2: Access to Educational Resources and Settings}

Both access to and a lack of access to educational resources and settings was discussed throughout the data as a contributing factor to the effectiveness of clinical education. Having access to a variety of educational resources and clinical settings was a valuable component of a strong clinical education curriculum. Access to multiple certified athletic trainers (ATCs) medical professionals at a single clinical site was mentioned as a benefit by many participants who reported that having more people to learn from was valuable. Clinical sites that provided a variety of resources such as modality equipment were also commonly cited by participants as being quality sites. Interestingly, there were also multiple participants who felt they had significant learning experiences at clinical sites who lacked multiple preceptors, adequate space, or current medical equipment. They felt they learned creativity by working with less, which is an experience they believed would help them in the future. By completing clinical experiences at sites with many resources and sites with limited resources, participants felt they were prepared to work in either type of environment.

\section{Theme 3: Mentorship and Professional Socialization}

The mentorship and professional socialization that clinical experiences provided was centralized around the preceptors. Participants describe the best clinical experiences being paired with a preceptor who demonstrated a willingness to teach, was a strong communicator and modeled strong professional behaviors. Similar to theme 2, this theme also had both positive and negative experiences as points of discussion. There were multiple participants who described poor role models who served as their preceptors but still reported that they were able to learn from the experience. They felt that having a preceptor who demonstrated poor professionalism or that simply dismissed them as a student gave them an idea of the type of athletic trainer they did not want to become. 
When participants described strong preceptors, they described mentors that encouraged learning, provided opportunity for students to practice skills, and who over all made the students feel like a valuable member of the AT team. Several participants also described influential preceptors as someone who demonstrated what it meant to be a life-long learner. One participant described her most influential preceptor as a mentor who not only taught her valuable lessons, but also taught her the value of constantly being a student. This preceptor would ask the AT student to teach them new skills they had learned in class and rather than simply answering questions the student would ask. They would encourage the student to research their question, therefore not only learning that direct content, but also the skill of research that allows for life-long learning.

\section{Theme 4: Commitment}

Time consuming, high standards, and hard work were all phrases that were commonly used to describe the experience of clinical education as an AT student. Participants agreed that outside of courses, clinical experiences took up a majority of their time. Participants felt that though the hours were long and demanding, the overall commitment required to be successful was worth the reward of the experience. One participant reported that his clinical experiences were "time consuming but also very worthwhile." Another added to this by explaining that clinical experiences "are gonna be what you make it." She went on to explain that clinical experiences effectiveness can be drastically affected by the student's commitment level and desire to have a valuable experience.

\section{DISCUSSION}

Clinical education has been cited as a contributor to the overall professional development of AT students..$^{1-6}$ Our participants supported this idea with their awareness of the role that clinical education played in their overall preparation for autonomous practice. One participant described her experience as "a lot of hard work, but at the end of the day totally worth it because it allows you to be prepared for when you're actually certified and actually have to do it on your own." Though previous research has focused on the role clinical education plays in the development of athletic trainers who are being educated at the undergraduate level, this study demonstrates that that concept can be extended to the graduate population as well. ${ }^{1-6}$ Graduate students recognize the value of real-life experience and appreciate the need to maximize clinical experiences. ${ }^{12,13}$ Though clinical experiences were described as demanding and time-consuming, they were never described as a burden or a waste of tinme. In fact, many participants recalled requesting extra clinical hours or opportunities above and beyond the program requirements.

Evidence suggests that graduate students have a stronger desire to learn vocational skills through hands-on learning because they can better envision why those skills will be useful when compared to undergraduate students. ${ }^{12,13}$ Though we only included a graduate student population in this study, participants in this study cited hands-on activities as being significant learning experiences. Some of the experiences shared were that of feeling a positive Lachman test for the first time, evaluating an athlete for a concussion, developing rehab plans for a non-compliant patient, and managing a sideline at an athletic event. All of these experiences were hands-on experiences that participants felt were significant learning experiences because they were real-life and not just envisioned in a classroom. Undergraduate students have described similar feelings toward the experiences they receive in clinical education. ${ }^{7}$

Many participants agreed that the preceptor plays a significant role in the overall experience that a student has in clinical education. In previous research, preceptors were given credit for controlling the amount of active participation opportunities that students have access to. $1.4,7$ When participants in this study reported a lack of active and hands-on learning, they also reported being assigned to preceptors who did not take an active role in their education. Preceptors who engage with their assigned AT student and who encourage or require their AT student to practice skills and make clinical decisions create a clinical education environment that encourages learning. Several participants recommended that participation in administrative tasks should be a requirement of clinical education. They shared feelings that administrative tasks such as writing emergency action plans and managing budget and inventory are learned about in class, but often students have little actual exposure in clinical experiences. Participants felt that exposure to these types of tasks helped them to gain valuable experience prior to autonomous practice. Participants reported that preceptors really controlled the amount of exposure that they had to administrative type tasks. Those who had exposure were encouraged by their preceptors, and those who did not have exposure reported their preceptors completed the administrative tasks without involving their AT student. Research supports the idea that preceptors who are actively engaged in a student's clinical experiences contribute to the overall learning environment. $4,5,10$

One finding of our research study that has been addressed on a limited basis in the literature is the role that the clinical site played in the overall learning of the student. Our study found that the clinical site itself did influence the overall experience. The amount of learning experiences that students had was affected by the patient population that the site served and the overall atmosphere of the site. The amount and types of resources at the sites were mentioned by many participants, but there was not a consensus on how important access to new and modern equipment and resources was. There was appreciation for both sites that offered many resources and sites that offered very little in the way of resources. This leads to the conclusion that a variety of experiences 
is beneficial, teaching students how to use new and modern modalities is helpful, and being innovative in treatment protocols when resources may be lacking stimulates creative thinking. Morin et al found that students feel most competent in their ability to treat traditional populations, such as athletes, because of extensive clinical education experiences at sites that treat athletes. ${ }^{3}$ This parallels the findings of our study and suggests that ATP faculty should develop clinical sites that give varied experiences both in population and in amount of resources available. Experience at clinical sites that offer a variety of resources will prepare students to work in many types of settings. Participants suggested that one aspect of clinical education that should be a requirement is experience at multiple types or levels of clinical sites. They expressed value in the varied clinical sites they were assigned to.

\section{Recommendations}

1. Clinical education should continue to be a required component of AT education because of the overall impact it has on student learning and preparation for autonomous practice.

2. AT program administration should seek out clinical preceptors who have a desire to educate AT students.

3. AT program administration should develop clinical education programs that provide exposure to a variety of clinicians, facilities, and patient populations.

4. AT program administration should encourage hands-on learning opportunities during clinical experiences.

\section{Limitations and Future Directions}

We explored clinical education from the professional master's student's perspective, thus only giving a voice to that population. While this population is obviously a key component of clinical education, it would be interesting to also gain some perspective from the preceptors who have mentored professional master's AT students. Thus, future studies should investigate the experiences of such preceptors.

The participant population was small in comparison to the number of people who have experienced this phenomenon and was also heavily female, with 10 of the 12 participants being female. The qualitative nature of this study and the desire to gather detailed data about the participant's experience provided a rich textual description but one that may not apply to all phenomenon members. This study did not specifically investigate how experiences may be different for male versus female students. Future research may be conducted to investigate specific clinical education experience differences for males and females and how same and opposite gender student-preceptor pairings may influence the experience. We would also suggest a quantitative study be conducted to parallel this study, investigating the key aspects or components that should be considered when designing or managing a clinical education program.

One other area of suggested future research would be to investigate how the quality of clinical experiences contributes to the student's ability to pass the Board of Certification (BOC) exam. BOC exam status for participants was not collected and therefore could not be evaluated in this study.

\section{CONCLUSIONS}

Our findings promote the use of clinical education as an educational requirement for professional master's AT students. Handson experiences, professional socialization, mentorship, and having a variety of experiences all contribute to the overall effectiveness and learning that occurs in clinical education. These experiences are valued by professional master's students and should be a continued requirement of all AT programs. Finally, by identifying the key components of a clinical education experience that encourage learning, program administrators can design a clinical education curriculum that will be most beneficial to AT students.

\section{REFERENCES}

1. Benes, S. S., Mazerolle, S. M., Bowman, T. G. The impact of clinical experiences from athletic training student and preceptor perspectives. Athl Train Educ J. 2014; 9(4):156-165. doi:10.4085/0904156.

2. Weidner, T. G., Henning, J. M. Historical perspectives of athletic training clinical education. J Athl Train. 2002; 37(4): S-222228.

3. Morin, G. E., Misasi, S., Davis, C., Hannah, C., Rothbard, M. Entry-level athletic trainers' self-confidence in clinical skill preparedness for treating athletic and emergent setting populations. Athl Train Educ J. 2014; 9(4): 166-173.

4. Aronson, P. A., Bowman, T. G., Mazerolle, S. M. Evaluating perceptions of culminating clinical education experiences of senior athletic training students. Athl Train Educ J. 2015; 10(3): 219-226.

5. Mazerolle, S. M., Eason, C. M., Nottingham, S., Barrett, J. L. Athletic training students' perceptions of mentorship in clinical education. Athl Train Educ J. 2016; 11(2): 72-81. 
6. Bowman, T. G., Dodge, T. M. Factors of persistence among graduates of athletic training education programs. J Athl Train. 2011; 46(6): 665-671.

7. Mazerolle, S. M., Bowman, T. G., Benes, S. S. Defining the engaging learning experience from the athletic training student perspective. Athl Train Educ J. 2014; 9(4): 182-189. doi:10.4085/0904182

8. Young, A., Klossner, J., Docherty, C. L., Dodge, T. M., Mensch, J. M. Clinical integration and how it affects student retention in undergraduate athletic training programs. J of Athl Train. 2013; 48(1): 68-78. doi:10.4085/1062-6050-48.1.22

9. Nottingham, S., Henning, J. Feedback in clinical education part 1: Characteristics of feedback provided by approved clinical instructors. J Athl Train. 2014; 49(1): 49-57.

10. Nottingham, S., Barrett, J., Mazerolle, S., Eason, C. Examining the role mentorship plays in the development of athletic training preceptors. Athl Train Educ J. 2016; 11(3): 127-137.

11. Commission on Accreditation of Athletic Training Education. Professional degree transition. Insight. 2015. Retrieved from http://caate.net/wp-content/uploads/2015/06/CAATE-Summer-2015-Insight-Newsletter.pdf

12. Artino, A. R., Stephens, J. M. Academic motivation and self-regulation: A comparative analysis of undergraduate and graduate students learning online. Internet High Educ. 2009; 12: 146-151.

13. Smith, L., Krass, I., Sainsbury, E., Rose, G. Pharmacy students' approaches to learning in undergraduate and graduate entry programs. Am J Pharm Educ. 2010; 74(6): 1-7.

14. Creswell, J. W. Qualitative Inquiry and Research Design: Choosing Among Five Approaches. Washington DC: Sage Publications; 2013.

15. Moustakas, C. Phenomenological Research Methods. Thousand Oaks, CA: Sage; 1994.

16. Schwandt, T. A. The Sage Dictionary of Qualitative Inquiry (4th ed.). Thousand Oaks, CA: Sage Publications; 2007.

17. Woodyatt, C. R., Finneran, C. A., \& Stephenson, R. In-person versus online focus group discussions: A comparative analysis of data quality. Qual Health Res. 2016; 26(6): 741-749.

\section{Appendix A. Data Collection Questions}

Semi-structured Interview Guide: The following is the data collection documents which will be utilized by the researcher.

1. Why did you choose to earn a degree in athletic training?

2. How would you classify yourself as a learner? What type of learning activities do you benefit the most from?

3. Tell me about your experiences as an athletic training student.

4. How would you describe your clinical education experiences?

5. What role do you believe that clinical education played in your education and learning?

6. What aspects of clinical education did you find most helpful in your learning and degree pursuit?

7. What aspects of clinical education did you find most frustrating? Tell me about some of the challenges you experienced with clinical education.

8. How do you feel that your clinical experiences have affected your ability to work as an ATC post-graduation?

9. Tell me about some of the clinical preceptors you were assigned to during clinical education experiences. Feel free to share both good and bad experiences.

10. Tell me about the most influential clinical preceptor you worked with during clinical education.

11. Tell me about some of the clinical sites you were assigned to during clinical education experiences. Feel free to share both good and bad experiences.

12. Tell me about the most influential clinical site you were assigned to work at during clinical education.

13. Tell me about a time when you can recall having a significant learning experience during clinical education. What made it significant or memorable?

\section{Appendix B. Journaling Prompts}

Please read the following journal prompts and respond in your own words. You may reflect on your thoughts and journal over time or complete this activity in one sitting. Any identifying characteristics will be removed or masked for publication to protect your identity. Once you have completed this activity please email your journal responses to Iwamsley@liberty.edu.

Prompt 1. Identify one preceptor that you feel was influential in your learning during clinical education and explain the role they played in learning and overall experience during clinical education. You may include any personal stories or feelings as to why 
that preceptor was significant and how they made a difference.

Prompt 2. Describe your most influential clinical site. Why was this site significant? How did this site prepare or fail to prepare you for clinical practice?

\section{Appendix C. Asynchronous Online Focus Group Discussion Forum Prompts}

1. What is your favorite memory of your AT clinical education?

2. What do you believe are characteristics of a strong clinical education experience?

3. If you could choose one requirement that is mandated for students during clinical education experiences what would it be? 